\title{
Papers
}

\section{Early enteral feeding versus "nil by mouth" after gastrointestinal surgery: systematic review and meta-analysis of controlled trials}

\author{
Stephen J Lewis, Matthias Egger, Paul A Sylvester, Steven Thomas Topic: 33;92;153;299
}

\begin{abstract}
Objective To determine whether a period of starvation (nil by mouth) after gastrointestinal surgery is beneficial in terms of specific outcomes. Design Systematic review and meta-analysis of randomised controlled trials comparing any type of enteral feeding started within 24 hours after surgery with nil by mouth management in elective gastrointestinal surgery. Three electronic databases (PubMed, Embase, and the Cochrane controlled trials register) were searched, reference lists checked, and letters requesting details of unpublished trials and data sent to pharmaceutical companies and authors of previous trials.
\end{abstract}

Main outcome measures Anastomotic dehiscence, infection of any type, wound infection, pneumonia, intra-abdominal abscess, length of hospital stay, and mortality.

Results Eleven studies with 837 patients met the inclusion criteria. In six studies patients in the intervention group were fed directly into the small bowel and in five studies patients were fed orally. Early feeding reduced the risk of any type of infection (relative risk $0.72,95 \%$ confidence interval 0.54 to $0.98, \mathrm{P}=0.036)$ and the mean length of stay in hospital (number of days reduced by $0.84,0.36$ to $1.33, \mathrm{P}=0.001)$. Risk reductions were also seen for anastomotic dehiscence $(0.53,0.26$ to $1.08, \mathrm{P}=0.080)$, wound infection, pneumonia, intra-abdominal abscess, and mortality, but these failed to reach significance $(\mathrm{P}>0.10)$. The risk of vomiting was increased among patients fed early $(1.27,1.01$ to 1.61 , $\mathrm{P}=0.046$ ).

Conclusions There seems to be no clear advantage to keeping patients nil by mouth after elective gastrointestinal resection. Early feeding may be of benefit. An adequately powered trial is required to confirm or refute the benefits seen in small trials.

\section{Introduction}

A period of starvation ("nil by mouth") is common practice after gastrointestinal surgery during which an intestinal anastomosis has been formed. The stomach is decompressed with a nasogastric tube and intravenous fluids are given, with oral feeding being introduced as gastric dysmotility resolves. ${ }^{1}$ The rationale of nil by mouth is to prevent postoperative nausea and vomiting and to protect the anastomosis, allowing it time to heal before being stressed by food. It is, however, unclear whether deferral of enteral feeding is beneficial.

Contrary to widespread opinion, evidence from clinical studies and animal experiments suggests that initiating feeding early is advantageous. Postoperative dysmotility predominantly affects the stomach and colon, with the small bowel recovering normal function 4-8 hours after laparotomy. ${ }^{1}$ Feeding within 24 hours after laparotomy is tolerated and the feed absorbed..$^{2}$ Gastrointestinal surgery is often undertaken in patients who are malnourished, ${ }^{4-6}$ which in severe cases is known to increase morbidity. ${ }^{7}$ In animals, starvation reduces the collagen content in anastomotic scar tissue $\mathrm{e}^{8}$ and diminishes the quality of healing, ${ }^{9}{ }^{10}$ whereas feeding reverses mucosal atrophy induced by starvation ${ }^{11}$ and increases anastomotic collagen deposition and strength. ${ }^{12}$ Experimental data in both animals and humans suggest that enteral nutrition is associated with an improvement in wound healing. ${ }^{13}$ Finally, early enteral feeding may reduce septic morbidity after abdominal trauma ${ }^{14}$ and pancreatitis. $^{15}$

Several clinical trials directly comparing strategies of early feeding with nil by mouth after elective gastrointestinal surgery have been performed. These studies, however, have not been systematically reviewed. We performed a systematic review and meta-analysis of randomised trials to assess the evidence on benefit and harm of early enteral feeding.

\section{Methods}

Eligibility criteria and literature search-Clinical trials were eligible if patients had undergone elective gastrointestinal surgery and were randomly allocated to receive either enteral feeding (within 24 hours after surgery) or the traditional management of nil by mouth and intravenous fluids with introduction of enteral fluids and diet as tolerated. We supplemented computerised searches of PubMed, Embase, and the Cochrane controlled trials register with checks of relevant reference lists. We wrote to trialists requesting additional data on outcomes not reported in publications and on trial methods. We also approached pharmaceutical

\author{
Department of \\ Medicine, \\ Addenbrooke's \\ Hospital, \\ Cambridge \\ CB2 2QQ \\ Stephen J Lewis \\ consultant \\ MRC Health \\ Services Research \\ Collaboration, \\ Department of \\ Social Medicine, \\ University of \\ Bristol, Bristol \\ BS8 2PR \\ Matthias Egger \\ senior lecturer in \\ epidemiology and \\ public health medicine \\ Department of \\ Surgery, Bristol \\ Royal Infirmary, \\ Bristol BS2 8HW \\ Paul A Sylvester \\ specialist registrar \\ Department of \\ Maxillofacial \\ Surgery, University \\ of Bristol, Bristol \\ BS1 2LY \\ Steven Thomas \\ senior lecturer \\ Correspondence to: \\ S Lewis \\ sjl@doctors.org.uk \\ BMJ 2001;323:1-5
}


Table 1 Characteristics of eleven trials of early enteral feeding after elective gastrointestinal surgery

\begin{tabular}{|c|c|c|c|c|c|c|c|c|c|}
\hline & \multicolumn{2}{|c|}{ No of patients } & \multirow[b]{2}{*}{ Type of feed } & \multirow{2}{*}{$\begin{array}{l}\text { Route of } \\
\text { feeding }\end{array}$} & \multicolumn{2}{|c|}{ Pathology (\%) } & \multicolumn{3}{|c|}{ Site of surgery (\%) } \\
\hline & Active & Control & & & Malignant & Benign & Upper & Lower & Hepatobiliary \\
\hline Schroeder et al, $1991^{13}$ & 16 & 16 & Standard & NJ & NR & NR & 0 & 100 & 0 \\
\hline Sagar et al, $1979^{20}$ & 15 & 15 & Elemental & NJ & NR & NR & 27 & 73 & 0 \\
\hline Binderow et al, $1994^{21}$ & 32 & 32 & Oral & Oral & NR & NR & 0 & 100 & 0 \\
\hline Reissman et al, $1995^{22}$ & 80 & 81 & Oral & Oral & NR & NR & 0 & 100 & 0 \\
\hline Carr et al, $1996^{23}$ & 14 & 14 & Standard & NJ & NR & NR & NR & NR & NR \\
\hline Beier-Holgersen et al, $1996^{24}$ & 30 & 30 & Standard & ND & 65 & 35 & 13 & 87 & 0 \\
\hline Ortiz et al, $1996^{25}$ & 95 & 95 & Oral & Oral & 87 & 23 & 0 & 100 & 0 \\
\hline Heslin et al, $1997^{26}$ & 97 & 98 & $\begin{array}{l}\text { Immune } \\
\text { enhancing }\end{array}$ & $\mathrm{J}$ & 93 & 7 & 51 & 0 & 49 \\
\hline Hartsell et al, $1997^{27}$ & 29 & 29 & Standard & Oral & 64 & 28 & 0 & 100 & 0 \\
\hline Watters et al, $1997^{28}$ & 15 & 16 & Standard & $\mathrm{J}$ & 93 & 7 & 96 & 0 & 4 \\
\hline Stewart et al, $1998^{29}$ & 40 & 40 & Oral & Oral & NR & NR & 0 & 100 & 0 \\
\hline
\end{tabular}

$\mathrm{NJ}=$ nasojejunal tube, $\mathrm{ND}=$ nasoduodenal tube, $\mathrm{J}=$ jejunostomy, $\mathrm{NR}=$ not reported.

companies that produce enteral feeds and asked whether they held data from unpublished trials.

Data extraction and outcomes-From each study we collected data on the site of surgery, whether an intestinal anastomosis was formed, whether the pathology was benign or malignant, the type of feed used, and the method of administration of the feed. The site of surgery was classified as pancreatic, hepatobiliary, upper gastrointestinal (proximal to the jejunum), or lower gastrointestinal (distal to the duodenum). Outcomes potentially related to feeding included anastomotic dehiscence, infection of any type, wound infection, pneumonia, intra-abdominal abscess, vomiting, mortality, and length of hospital stay. The unplanned reinsertion of a nasogastric tube was recorded. The data were extracted independently by two of the authors (SJL and PAS), checked for consistency by another author (ST), and sent to the trialists for review.

Assessment of methodological quality-Two of us (ST and ME) independently assessed the two dimensions of methodological quality that empirically have been shown to be associated with biased estimates of treatment effects: adequacy of concealment of allocation to treatment groups and double blinding. ${ }^{16}$ Differences in assessment were resolved by consensus.

Analysis-We combined results from individual studies on the relative risk scale using fixed effects meta-analysis. ${ }^{18}$ Data on length of hospital stay were pooled with non-standardised mean differences. We used a $\chi^{2}$ test to test for homogeneity of relative risks. We used funnel plots to determine the presence of publication bias and related biases and performed a statistical test of funnel plot asymmetry. ${ }^{19}$ In a sensitivity analysis we excluded data from patients who did not have an intestinal anastomosis from analyses of anastomotic dehiscences. These patients had abdominoperineal resections or stoma creations. In a planned subgroup analysis we examined whether the risk of anastomotic dehiscence differed according to whether the anastomosis was proximal or distal to the site of feeding. Results are presented as relative risks (95\% confidence intervals). All analyses were performed with Stata version 6.0 (StataCorp, College Station, Texas).

\section{Results}

Characteristics of trials, patients, and interventions We identified 13 randomised controlled trials, all of which were published in English. ${ }^{130-31}$ We excluded two of these trials because no information on relevant outcomes was given, and attempts to obtain unpublished data from the authors were unsuccessful. ${ }^{30} 31$ Additional unpublished data were obtained for six of

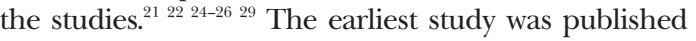
in $1979^{20}$; however, most were published between 1995 and 1998.

Patients had a wide variety of gastrointestinal conditions. Table 1 gives details of the 11 trials that we included. Six studies included only lower gastrointestinal surgery. ${ }^{132122} 252729$ Six studies did not state the underlying pathology of the study participants, the five remaining trials included both benign and malignant conditions. Thirty one patients from five trials underwent abdominoperineal resections or stoma creation and had no anastomosis. ${ }^{2022} 242527$ In six studies patients in the intervention group were fed directly into the small bowel, and in five studies patients were fed orally. In four studies feeding was started within six hours after surgery. ${ }^{13} 232428$ In the nine remaining studies it was started within 24 hours. One trial used a placebo feed (water). ${ }^{24}$

\section{Methodological quality of trials}

Reporting on concealment of allocation of treatment and blinding was poor. In three trials allocation was concealed with sealed envelopes, ${ }^{23}{ }^{24} 26$ and one trial used an open table with random numbers,${ }^{20}$ but in the remaining studies the exact method of randomisation was unclear. In the study by Heslin et al the outcomes were assessed by "a physician not associated with the surgical team." ${ }^{26}$ In all other studies outcome assessment was probably open, although this was explicitly stated in only one report. ${ }^{28}$

\section{Outcomes}

The effects of early feeding on anastomotic dehiscence, infections, vomiting, and mortality are detailed in table 2 and summarised in the figure. Occurrence of anastomotic dehiscence was reported in eight of the 11 trials. Table 3 gives detailed information on the number of events-for example, the risk of dehiscence ranged from $2 \%(2 / 95)$ to $7 \%(2 / 30)$ in early feeding groups and from $1 \%(1 / 81)$ to $25 \%(4 / 16)$ in control groups. Seven trials showed that early feeding led to a reduction in risk of anastomotic dehiscence (table 2) with a combined relative risk of 0.53 (95\% confidence interval 0.26 to $1.08, \mathrm{P}=0.080$ ) and no evidence of heterogeneity between studies $\left(\chi^{2}=2.10, \mathrm{P}=0.96\right)$. Results were similar when 31 patients in whom no 
Table 2 Relative risk $(95 \% \mathrm{Cl})$ of anastomotic dehiscence, infection, and death in eleven randomised trials of early enteral nutrition

\begin{tabular}{|c|c|c|c|c|c|c|c|}
\hline & \multirow[b]{2}{*}{$\begin{array}{l}\text { Anastomotic } \\
\text { dehiscence }\end{array}$} & \multicolumn{4}{|c|}{ Infections } & \multirow[b]{2}{*}{ Vomiting } & \multirow[b]{2}{*}{ Death } \\
\hline & & Any infection & Wound infection & Pneumonia & $\begin{array}{l}\text { Intra-abdominal } \\
\text { abscess }\end{array}$ & & \\
\hline$\overline{\text { Sagar et al }{ }^{20}}$ & 0.33 (0.01 to 7.58$)$ & $0.71(0.29$ to 1.75$)$ & 0.60 (0.17 to 2.07$)$ & NR & $1.00(0.16$ to 6.20$)$ & NR & NR \\
\hline$\overline{\text { Binderow et } \mathrm{al}^{21}}$ & NR & NR & NR & NR & NR & 1.75 (0.85 to 3.56$)$ & NR \\
\hline Reissman et al ${ }^{22}$ & 0.34 (0.01 to 8.16$)$ & 1.27 (0.35 to 4.54$)$ & 2.02 (0.19 to 21.9$)$ & 0.34 (0.01 to 8.16$)$ & 1.01 (0.06 to 15.9$)$ & 1.56 (0.78 to 3.13$)$ & NR \\
\hline$\overline{\text { Carr et } \mathrm{al}^{23}}$ & NR & 0.14 (0.01 to 2.53 ) & NR & NR & NR & NR & 0.33 (0.01 to 7.54$)$ \\
\hline$\overline{B e i e r-H o l g e r s e n ~ e t ~} \mathrm{al}^{24}$ & 0.50 (0.10 to 2.53$)$ & $0.14(0.04$ to 0.57 & 0.10 (0.01 to 0.73$)$ & 0.5 (0.05 to 5.22) & $0.20(0.01$ to 4.00$)$ & 0.88 (0.55 to 1.42$)$ & 0.50 (0.01 to 2.53$)$ \\
\hline Ortiz et al ${ }^{25}$ & 0.50 (0.09 to 2.67$)$ & 0.80 (0.33 to 1.94$)$ & 0.83 (0.26 to 2.64$)$ & $1.00(0.14$ to 6.95$)$ & $1.00(0.06$ to 15.8$)$ & NR & NR \\
\hline Heslin et $\mathrm{al}^{26}$ & $0.76(0.17$ to 3.30$)$ & 0.95 (0.62 to 1.44$)$ & 1.64 (0.71 to 3.78$)$ & $0.43(0.12$ to 1.63$)$ & $2.02(0.19$ to 21.9$)$ & 1.38 (0.86 to 2.21$)$ & 0.67 (0.12 to 3.94$)$ \\
\hline Hartsell et al ${ }^{27}$ & $0.33(0.01$ to 7.86$)$ & 3.00 (0.13 to 70.7$)$ & NR & $3.00(0.13$ to 70.7$)$ & NR & 1.40 (0.75 to 2.62$)$ & 0.33 (0.01 to 7.86$)$ \\
\hline Watters et $\mathrm{a}^{28}$ & 0.27 (0.03 to 2.12$)$ & NR & NR & NR & NR & NR & NR \\
\hline Stewart et a ${ }^{29}$ & 3.00 (0.16 to 71.5$)$ & 0.56 (0.20 to 1.51$)$ & 0.11 (0.01 to 2.00$)$ & 1.00 (0.06 to 15.4$)$ & NR & 1.00 (0.55 to 1.82$)$ & 0.33 (0.01 to 7.95$)$ \\
\hline Combined relative risk & 0.53 (0.26 to 1.08$)$ & 0.72 (0.54 to 0.98$)$ & 0.71 (0.44 to 1.17 ) & 0.73 (0.33 to 1.59$)$ & 0.87 (0.31 to 2.42$)$ & 1.27 (1.01 to 1.61 ) & 0.48 (0.18 to 1.29$)$ \\
\hline $\begin{array}{l}\mathrm{P} \text { value from test for } \\
\text { heterogeneity }\end{array}$ & 0.96 & 0.22 & 0.074 & 0.85 & 0.84 & 0.52 & 0.99 \\
\hline
\end{tabular}

$\mathrm{NR}=$ not reported or no events occurred.

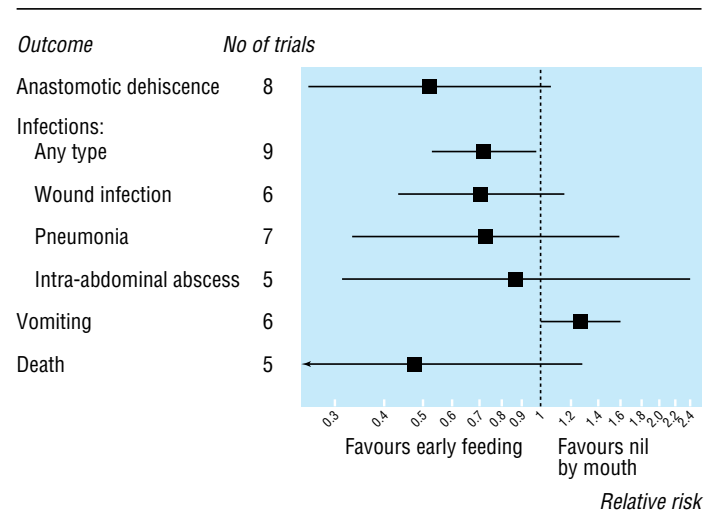

Risk of anastomotic dehiscence, infections, vomiting, and death after elective gastrointestinal surgery: results from meta-analyses of randomised trials comparing early enteral feeding with regimen of nil by mouth

anastomosis had been formed were excluded from the denominator of five trials (combined relative risk 0.54, 0.26 to 1.09). ${ }^{2022} 2225$ There was little evidence that results differed between the two studies in which the anastomosis was known to be proximal to the site of feeding ${ }^{28}$ and the six trials in which it was distal $(\mathrm{P}=0.42$ for interaction).
The risk of any type of infection was reported in all but two trials (table 2). ${ }^{21}{ }^{28}$ Absolute risks ranged from $3 \%(1 / 29)$ to $30 \%(29 / 97)$ in the early feeding groups and from $5 \%(4 / 81)$ to $47 \%(14 / 30)$ in the control groups (table 3 ). The combined relative risk was 0.72 ( 0.54 to 0.98$)$, indicating a significant $(\mathrm{P}=0.036)$ reduction in the risk of infection, with little evidence of heterogeneity between trials $\left(\chi^{2}=10.7, \mathrm{P}=0.22\right)$. Similar reductions were observed for wound infection and pneumonia (figure). There was an increase in the risk of vomiting among patients fed early (1.27, 1.01 to $1.61, \mathrm{P}=0.045)$. Absolute risks ranged from $21 \%$ $(17 / 80)$ to $50 \%(15 / 30)$ in the early feeding groups and from $14 \%(11 / 81)$ to $57 \%(17 / 30)$ in the control groups (table 3). When nasogastric tubes were not placed routinely at the time of surgery the rate of placement because of nausea and vomiting was higher in patients fed early $(1.21,0.73$ to $1.99, \mathrm{P}=0.46)$.

Mortality was reported in all but two studies, ${ }^{21}{ }^{28}$ but deaths occurred in only five (table 2). When reported, death occurred in hospital except for in one study in which 30 day mortality was reported. ${ }^{24}$ Mortality ranged from none to $7 \%(2 / 30)$ in the early feeding groups and 13\% (4/30) in the control groups (table 3). There were four deaths in the early feeding groups compared with 10 deaths in control groups (relative risk $0.48,0.18$ to $1.29, \mathrm{P}=0.15$ ).

Table 3 Number of patients with complications reported in eleven randomised trials of early enteral nutrition

\begin{tabular}{|c|c|c|c|c|c|c|c|c|c|c|c|c|c|c|c|}
\hline & \multirow{3}{*}{$\begin{array}{c}\text { No of } \\
\text { patients } \\
\text { (active/ } \\
\text { control) }\end{array}$} & \multirow{2}{*}{\multicolumn{2}{|c|}{$\begin{array}{l}\text { Anastomotic } \\
\text { dehiscence }\end{array}$}} & \multicolumn{8}{|c|}{ Infections } & & & & \\
\hline & & & & \multicolumn{2}{|c|}{ Any infection } & \multicolumn{2}{|c|}{ Wound infection } & \multicolumn{2}{|c|}{ Pneumonia } & \multicolumn{2}{|c|}{$\begin{array}{l}\text { Intra-abdominal } \\
\text { abscess }\end{array}$} & \multicolumn{2}{|c|}{ Vomiting } & \multicolumn{2}{|c|}{ Death } \\
\hline & & Active & Control & Active & Control & Active & Control & Active & Control & Active & Control & Active & Control & Active & Control \\
\hline Sagar et al ${ }^{20}$ & $15 / 15$ & 0 & 1 & NR & NR & 3 & 5 & NR & NR & 2 & 2 & NR & NR & 0 & 0 \\
\hline Schroeder et al ${ }^{13}$ & $16 / 16$ & 0 & 0 & 1 & 0 & 0 & 0 & 1 & 0 & 0 & 0 & NR & NR & 0 & 0 \\
\hline Binderow et $\mathrm{al}^{21}$ & $32 / 32$ & NR & NR & NR & NR & NR & NR & NR & NR & NR & NR & 14 & 8 & NR & NR \\
\hline Reissman et al ${ }^{22}$ & $80 / 81$ & 0 & 1 & 5 & 4 & 2 & 1 & 0 & 1 & 1 & 1 & 17 & 11 & 0 & 0 \\
\hline Beier-Holgersen et a $\left.\right|^{24}$ & $30 / 30$ & 2 & 4 & 2 & 14 & 1 & 10 & 1 & 2 & 0 & 2 & 15 & 17 & 2 & 4 \\
\hline Ortiz et al ${ }^{25}$ & $95 / 95$ & 2 & 4 & 8 & 10 & 5 & 6 & 2 & 2 & 1 & 1 & NR & NR & 0 & 0 \\
\hline Heslin et a ${ }^{26}$ & $97 / 98$ & 3 & 4 & 29 & 31 & 13 & 8 & 3 & 7 & 2 & 1 & 30 & 22 & 2 & 3 \\
\hline Hartsell et $\mathrm{al}^{27}$ & $29 / 29$ & 0 & 1 & 1 & 0 & 0 & 0 & 1 & 0 & 0 & 0 & 14 & 10 & 0 & 1 \\
\hline Watters et $\mathrm{al}^{28}$ & $15 / 16$ & 1 & 4 & NR & NR & $N R$ & NR & $N R$ & $N R$ & $N R$ & $N R$ & $N R$ & NR & NR & NR \\
\hline Stewart et al ${ }^{29}$ & $40 / 40$ & 1 & 0 & 5 & 9 & 0 & 4 & 1 & 1 & 0 & 0 & 14 & 14 & 0 & 1 \\
\hline
\end{tabular}

NR=not reported 
Length of hospital stay was reported in all 11 studies. When combining data for meta-analysis we estimated the mean length of stay from the median for one trial. ${ }^{20}$ We estimated standard deviations (SD) by dividing ranges by factor 4 for two trials. ${ }^{20}{ }^{21}$ The mean length of stay ranged from 6.2 days to 14.0 days in early feeding groups and from 6.8 days to 19.0 days in control groups. Combined results showed a significant reduction by 0.84 day ( 0.36 to 1.33 days, $\mathrm{P}=0.001$ ), with some evidence of heterogeneity between studies $\left(\chi^{2}=16.2, \mathrm{P}=0.094\right)$. Results were similar when we excluded the two trials with incomplete data. ${ }^{21}$

Two major complications of feeding were reported in patients fed via jejunostomies: one broke and migrated into the abdomen ${ }^{26}$ and one left a prolonged fistula after it was removed. ${ }^{26}$

\section{Funnel plots}

We examined funnel plots for all nine outcomes (the seven shown in table 2 plus length of stay and replacement of nasogastric tubes). There was no clear evidence of asymmetry in any of these plots $(\mathrm{P}>0.10$ by regression test $\left.{ }^{19}\right)$, except for mortality $(\mathrm{P}=0.068)$.

\section{Discussion}

This meta-analysis yielded three principal findings. Firstly, there does not seem to be a clear advantage in keeping patients nil by mouth after elective gastrointestinal resection. Secondly, in these patients early feeding may be beneficial. Thirdly, we believe these results indicate the necessity for an adequately powered clinical trial to assess early enteral feeding in patients undergoing elective gastrointestinal surgery.

\section{Complications after operation}

Anastomotic dehiscence is a major complication of gastrointestinal surgery with considerable morbidity and mortality. ${ }^{32}$ The combined estimate failed to reach conventional levels of significance but indicates that early feeding may reduce the risk of dehiscence. Reporting on factors that could have modified the effect of early feeding, ${ }^{32-34}$ such as the experience of the surgeon, whether the resections were from the large or small bowel, the length of the operation time, postoperative pain control, the use of antibiotics, and the success of the operation, was incomplete. Furthermore, the definition of dehiscence varied between trials. However, the estimated effect in eight out of nine studies that reported anastomotic dehiscence indicated benefit and was similar among patients fed proximally or distally to their anastomosis.

A significant relative reduction in the risk of infection of any type was observed for patients receiving early enteral nutrition, with the greatest reduction seen in the frequency of wound infections. In most of the trials assessed infections were not clearly defined. In absolute terms results were heterogeneous, with the number of patients who would need to be treated to prevent one infection of any type ranging from three ${ }^{24}$ to $58 .^{26}$

\section{Length of hospital stay}

The length of hospital stay after surgery was reduced in eight of the eleven studies. Overall the reduction corresponds to about one day, which is economically important. Reduction in complication rates may explain this

\section{What is already known on this topic}

Enteral feeding within 24 hours after gastrointestinal surgery is tolerated

Theoretically, early enteral feeding improves tissue healing and reduces septic complications after gastrointestinal surgery

\section{What this study adds}

There is no benefit in keeping patients "nil by mouth" after gastrointestinal surgery

Septic complications and length of hospital stay were reduced in those patients who received early enteral feeding

In patients who received early enteral feeding there were no significant reductions in incidence of anastomotic dehiscence, wound infection, pneumonia, intra-abdominal abscess, and mortality

observation, as might a faster return of gastrointestinal function. Early postoperative feeding after nongastrointestinal surgery has also been shown to reduce length of stay in hospital. ${ }^{35}{ }^{36}$ Although not significant, the direction of effect suggested a reduced risk of postoperative death among patients who received early enteral feeding in all five studies in which mortality occurred. There were insufficient data to comment on the causes of death. Reductions in mortality tended to be larger in smaller studies, which may be due to chance, publication bias, or lower methodological quality of smaller studies. ${ }^{19}$ Mortality was one out of nine outcomes examined, and no evidence of small study bias was evident for the other outcomes. The association found for mortality was probably a chance finding.

\section{Statistical quality}

The 11 randomised trials identified were clinically heterogeneous and most of them were small and of doubtful methodological quality. Combination trials that differ in terms of underlying condition, operation, and intervention may be inappropriate. However, we were interested in the pragmatic comparison of early versus deferred feeding strategies after gastrointestinal surgery and not in differences between feed types or specific routes of feeding. It is noteworthy that the effect of early nutrition seemed to be homogeneous across a set of trials that were clearly heterogeneous in clinical terms. Our ability to detect heterogeneity between trials, however, was limited by the small number of trials and by the often inadequate reporting. For example, definition of the patients' preexisting nutritional state and severity of underlying disease was generally poor. The method of randomisation and blinding of outcome assessment was also not described in sufficient detail, which means that uncertainty regarding the methodological quality of trials remains. In particular, the identical or closely similar number of patients in comparison groups in these trials must be of concern. ${ }^{37}$ This could occur only if blocked randomisation with a small block size had 
been used. Blocked or stratified randomisation, however, was mentioned in only two trials. ${ }^{24} 28$

\section{Conclusion}

There is little evidence from these trials that keeping patients nil by mouth is beneficial after elective gastrointestinal resection. Although the data are clearly insufficient to conclude that early feeding is of proved benefit, we believe that there is a good case for an adequately powered clinical trial to assess early enteral feeding in such patients. With anastomotic dehiscence as the primary end point, such a trial would need to enrol about 1000 patients in each arm and would therefore involve several centres.

We thank the authors who provided additional data: $\mathrm{R}$ Beier-Holgersen, B Stewart, S Wexner, J E Fischer, M F Brennan, and $\mathrm{H}$ Ortiz. We also thank the following manufacturers of enteral feeds for assisting in the collection of data: Nutricia, Fresenius Kabi, Novartis Nutrition UK, Ross Products, Clintec Nutrition, Nestlé (Clinical Nutrition), SHS International, Mead Johnson Nutrition.

Contributors: The data were extracted independently by SJL and PAS and checked for consistency by ST. ST and ME assessed the two dimensions of methodological quality. SJL wrote to al the trialists and feed companies requesting additional data and coordinated the writing of the paper. ME advised on the literature search and performed quality assessments and statistical analyses. All the authors contributed to the writing of the final draft of the manuscript. SJL is guarantor for the paper.

Funding: None.

Competing interests: None declared.

Catchpole BN. Smooth muscle and the surgeon. Aust $N$ Z J Surg 1989;59:199-208.

2 Moss G. Maintenance of gastrointestinal function after bowel surgery and immediate enteral full nutrition. II. Clinical experience, with objective demonstration of intestinal absorption and motility. J Parenter Enteral Nutr 1981:5:215-20.

3 McCarter MD, Gomez ME, Daly JM. Early postoperative enteral feeding following major upper gastrointestinal surgery. J Gastrointest Surg $1996 ; 1: 278-85$.

McWhirter JP, Pennington CR. Incidence and recognition of malnutrition in hospital. $B M J$ 1994;308:945-8.

5 Hill GL, Pickford I, Young GA, Schorah CJ, Blackett RL, Burkinshaw L, et al. Malnutrition in surgical patients: an unrecognised problem. Lance 1977;i:689-92.

6 Lennard-Jones JE. A positive approach to nutrition as a treatment. London: King's Fund Centre, 1992

7 The Veterans Affairs Total Parenteral Nutrition Cooperative Study Group. Perioperative total parenteral nutrition in surgical patients. NEngl JMed 1991;325:525-2.

8 Uden P, Blomquist P, Jiborn H, Zederfeldt B. Impact of long-term relative bowel rest on conditions for colonic surgery. Am J Surg 1988;156:381-5.

9 Irvin TT, Hunt TK. Effect of malnutrition on colonic healing. Ann Surg 1974:180:765-72

10 Ward MW, Danzi M, Lewin MR, Rennie MJ, Clark CG. The effects of subclinical malnutrition and refeeding on the healing of experimental colonic anastomoses. Br J Surg 1982;69:308-10.

11 Goodlad RA, Al-Mukhtar MY, Ghatei MA, Bloom SR, Wright NA. Cell proliferation, plasma enteroglucagon and plasma gastrin levels in starved and refed rats. Virchous Arch B Cell Pathol Ind Mol Pathol 1983,43555-62.

12 Moss G, Greenstein A, Levy S, Bierenbaum A. Maintenance of GI function after bowel surgery and immediate enteral full nutrition. I. Doubling of canine colorectal anastomotic bursting pressure and intestinal wound mature collagen content. Clinical experience, with objective demonstration of intestinal absorption and motility. J Parenter Enteral Nut 1980;4:535-8.

13 Schroeder D, Gillanders L, Mahr K, Hill GL. Effects of immediate postoperative enteral nutrition on body composition, muscle function, and wound healing J Parenter Enteral Nutr 1991:15:376-83.

14 Moore FA, Moore EE, Jones TN, McCroskey BL, Peterson VM. TEN versus TPN following major abdominal trauma-reduced septic morbidity. JTrauma 1989:29:916-22.

15 Windsor AC, Kanwar S, Li AG, Barnes E, Guthrie JA, Spark JI, et al. Compared with parenteral nutrition, enteral feeding attenuates the acute phase response and improves disease severity in acute pancreatitis. Gu 1998;42:431-5.

16 Schulz KF, Chalmers I, Hayes RJ, Altman DG. Empirical evidence of bias. Dimensions of methodological quality associated with estimates of treatment effects in controlled trials. JAMA 1995;273:408-12.

17 Moher D, Pham B, Jones A, Cook DJ, Jadad AR, Moher M, et al. Does quality of reports of randomised trials affect estimates of intervention efficacy reported in meta-analyses? Lancet 1998;352:609-13.

18 Deeks JJ, Altman DG, Bradburn MJ. Statistical methods for examining heterogeneity and combining results from several studies in metaanalysis. In: Egger M, Smith DG, Altman DG, editors. Systematic reviews in health care: meta-analysis in context. London: BMJ Publishing, 2001:285312 .

19 Egger M, Davey Smith G, Schneider M, Minder C. Bias in meta-analysi detected by a simple, graphical test. BMJ 1997;315:629-34.

20 Sagar S, Harland P, Shields R. Early postoperative feeding with elemental diet. $B M J 1979 ;$; $293-5$.

21 Binderow SR, Cohen SM, Wexner SD, Nogueras JJ. Must early postoperative oral intake be limited to laparoscopy? Dis Colon Rectum 1994:37:584-9.

22 Reissman P, Teoh TA, Cohen SM, Weiss EG, Nogueras JJ, Wexner SD. I early oral feeding safe after elective colorectal surgery? A prospective randomised trial. Ann Surg 1995;222:73-7.

23 Carr CS, Ling KD, Boulos P, Singer M. Randomised trial of safety and efficacy of immediate postoperative enteral feeding in patients undergoing gastrointestinal resection. BMJ 1996;312:869-71.

24 Beier-Holgersen R, Boesby S. Influence of postoperative enteral nutrition on postsurgical infections. Gut 1996;39:833-5.

25 Ortiz H, Armendariz P, Yarnoz C. Is early postoperative feeding feasible in elective colon and rectal surgery? Int J Colorectal Dis 1996;11:119-121.

26 Heslin MJ, Latkany L, Leung D, Brooks AD, Hochwald SN, Pisters PW, et al. A prospective, randomized trial of early enteral feeding after resection of upper gastrointestinal malignancy. Ann Surg 1997;226:567-680.

27 Hartsell PA, Frazee RC, Harrison JB, Smith RW. Early postoperative feeding after elective colorectal surgery. Arch Surg 1997;132:518-21.

28 Watters JM, Kirkpatrick SM, Norris SB, Shamji FM, Wells GA. Immediate postoperative enteral feeding results in impaired respiratory mechanics and decreased mobility. Ann Surg 1997;226:369-80.

29 Stewart BT, Woods RJ, Collopy BT, Fink RJ, Mackay JR, Keck JO. Early feeding after elective open colorectal resections: a prospective randomized trial. Aust N Z J Surg 1998;68:125-8.

30 Ryan JA Jr, Page CP, Babcock L. Early postoperative jejunal feeding of elemental diet in gastrointestinal surgery. Am Surg 1981;47:393-403.

31 Hoover HC Jr, Ryan JA, Anderson EJ, Fischer JE. Nutritional benefits of immediate postoperative jejunal feeding of an elemental diet. Am J Surg 1980;139:153-9.

32 Wheeler JM, Gilbert JM. Controlled intraoperative water testing of left-sided colorectal anastomoses: are ileostomies avoidable. Ann $R$ Coll Surg Engl 1999;81:105-8.

33 Irvin TT, Goligher JC. Aetiology of disruption of intestinal anastomoses. Br J Surg 1973;60:461-4.

34 Thornton FJ, Barbul A. Healing in the gastrointestinal tract. Surg Clin North Am 1997;77:549-73.

35 Delmi M, Rapin CH, Bengoa JM, Delmas PD, Vasey H, Bonjour JP. Dietary supplementation in elderly patients with fractured neck of the femur. Lancet 1990;335:1013-6.

36 Schilder JM, Hurteau JA, Look KY, Moore DH, Raff G, Stehman FB, et al. A prospective controlled trial of early postoperative oral intake following major abdominal gynecologic surgery. Gynecol Oncol 1997;67:235-40.

37 Schulz KF, Chalmers I, Grimes DA, Altman DG. Assessing the quality of randomization from reports of controlled trials published in obstetrics and gynecology journals. JAMA 1994;272:125-8.

(Accepted 30 May 2001) 